\title{
Successful Therapeutic Management of Ivermectin Toxicity in Deoni Calf
}

\author{
Bhikane Anil Udhavrao ${ }^{1 *}$, Jadhav Ravindra Kaka ${ }^{2}$ and Anand Mohan ${ }^{2}$ \\ ${ }^{1}$ Department of Veterinary Clinical Medicine, Ethics \& Jurisprudence, India \\ ${ }^{2}$ College of Veterinary and Animal Sciences, India
}

Submission: April 14, 2017; Published: May 05, 2017

*Corresponding author: Bhikane Anil Udhavrao, Department of Veterinary Clinical Medicine, COVAS, Udgir, India, Tel: 91-2385 257359;

Email: draubhikane@rediffmail.com

\begin{abstract}
A month old, 39kg Deoni calf was admitted to Teaching Veterinary Clinical Complex, with history of salivation, labored respiration abnormality in gait and loss of appetite. History revealed administration of dewormer bolus containing combination of fenbendazole ( $300 \mathrm{mg}$ ) \& ivermectin $(100 \mathrm{mg})$. Clinical examination revealed salivation, normal body temperature, tachycardia, tachypnea, depression, incoordination in gait and tremors. Based on clinical signs and history of administration of overdose of dewormer containing ivermectin the case was diagnosed as Ivermectin toxicity.The calf was treated with supportive therapy of fluids, amoxicillin plus cloxacillin, dexamethasone and chlorpheniramine maleate daily for five days. Clinical improvement started from day second while complete clinical recovery was observed on fourth day of treatment. As antidote is not available, such cases of accidental administration of overdose of ivermectin could be managed successfully with supportive treatment and patient monitoring.
\end{abstract}

Keywords: Ivermectin; Toxicity; Calf; Treatment

\section{Introduction}

Ivermectin is endectoparasiticide of Macrocyclic lactone class which is commonly used as broad spectrum an the lmintics. It has wide spectrum of activity against gastrointestinal and lung nematodes, mites, ticks, biting flies and larvae of parasitic dipteran flies [1,2]. It is also active against larvae of canine heartworm Dirofileria immitis [3]. Ivermectin acts by binding GABA-gated chloride and invertebrate's specific glutamatedgated anion channel in peripheral neuromuscular synapses, suppressing conduction of nerve impulse [4]. Dewormer toxicity is rare in farm animals unless and until there is overdosing of the drug. Also the antihelmintics with narrow margin of safety are more prone for toxicosis in animals due to faulty managemental practices leading to administration of overdose of dewormer and such incidences have been reported by various workers [5-7]. The present communication puts on record rare case of ivermectin toxicity in calf and its successful therapeutic management.

\section{Case Report and Results}

A month old Deoni calf weighing $39 \mathrm{~kg}$ was admitted to Teaching Veterinary Clinical Complex of College of Veterinary and Animal Sciences, Udgir with complaint of difficulty in breathing and dullness, difficulty in walking and gradual loss of appetite since two days. Managemental history from owner revealed administration of dewormer bolus having combination of ivermectin (100mg/bolus) and fenbedazole (3000mg/ bolus) as the calf was exhibiting sings of soil licking, arching of back and colic suggestive of worm load.

Clinical examination revealed dullness, severe weakness with incoordination while walking and preferred recumbency for long time. Examination of head revealed sticky salivation, slight nasal discharge and cyanotic mucus membranes. Body temperature $\left(101^{\circ} \mathrm{F}\right)$ was normal while heart rate $(120 / \mathrm{min})$ and respiration rates $(32 / \mathrm{min})$ were elevated. Distant examination of calf revealed shivering, tremors and incoordination of gait. Pelleted feces with mucus and yellowish colored urine were observed in ailing calf. Hematology revealed leukocytosis (29.68×10\%/ $\mu \mathrm{l})$, accompanied by granulocytosis $\left(19.82 \times 10^{9} / \mu \mathrm{l}\right)$, normal erythrogram (TEC- $9.85 \times 1012 / \mu \mathrm{l}, \mathrm{Hb}-12.9 \mathrm{gm} / \mathrm{dl}$, HCT- $40 \%$ ) and normal thrombocyte $\left(362 \times 10^{9} / \mu \mathrm{l}\right)$ count. On the basis of history and clinical signs the case was diagnosed as Ivermectin toxicity.

The calf was treated with fluids (Dextrose 5\%@1 liter/ day in two divided doses iv), amoxicillin+cloxacillin @10 mg $/ \mathrm{kg}$ 
iv, vitamin B complex (B1+B2+B6) @ 3ml iv, chlorpheniramine maleate@0.2mg/kg im, Dexamethasone @ 0.3mg/kg iv daily for five days and combination of etofylline $(84.7 \mathrm{mg} /$ $\mathrm{ml}+$ theophylline $25.3 \mathrm{mg} / \mathrm{ml}$ )@2 $\mathrm{ml}$ im twice a day for one day. Recovery from all clinical parameters was started from second day except respiratory distress. Milk intake initiated by calf since second day with normal defecation and urination. Salivation and nasal discharge was completely resolved on third day with slight tachycardia. The same treatment was continued for five days with tapering dose of dexamethasone.

\section{Discussion}

Ivermectin is a broad spectrum antihelmintic as well as ectoparasiticide that belongs to Avermectin class. It acts by binding GABA-gated chloride and invertebrates specific glutamated-gated anion channel in peripheral neuromuscular synapses, suppressing conduction of nerve impulse [4].

Over dose of fenbendazole and ivermectin combination was reported in ailing calf but compared to ivermectin, margin of safety is higher for fenbendazole. In the present case calf received fenbendazole at the dose rate of $75 \mathrm{mg} / \mathrm{kg}$ body weight. However oral administration of fenbendazole to cattle in doses up to $2 \mathrm{gm} /$ $\mathrm{kg}$ body weight is well tolerated without any adverse effect [8]. Ivermectin has minimum 10 fold margin of safety in ruminants [9] but in ailing calf ivermectin was administered with around 13 times higher the standard dose that might have resulted in toxicity symptoms. Differences in pharmacokinetic properties of Ivermectin across various species of animal have been reported thereby signifying the variation in the margin of safety dose and degree of signs of toxicity due to overdosing [4].

The signs of ivermectin toxicosis observed in animals are mydriasis and depression followed by ataxia, recumbency and death $[3,9]$. Ivermectin toxicity is characterized by GABA mediated cholinergic effects leading to symptoms like salivation, difficulty in breathing, diarrhea and ataxia in calves [4]. The severity of toxicity varies with the route of administration of ivermectin depending up on pharmacokinetic properties. The bioavailability of ivermectin is highest with SC route with overall higher bioavailability in plasma with longer duration of action and better efficacy compared to oral route. Also intraruminal administration of ivermectin in cattle revealed that the bioavailability was $26 \%$ of that following SC administration [10]. Lower absorption of Ivermectin by oral route could be influenced by P-glycoprotein which is also present in intestinal epithelium leading to comparatively less bioavailability $[2,11]$. Therefore in spite of very high dose of ivermectin, the severity of clinical signs of poisoning was less probably due to reduced bioavailability of ivermectin up on oral administration in ailing calf.
Ivermectin toxicosis was reported in three Quarter Horses orally administered with 1 dose of $1.87 \%$ Ivermectin paste. Clinical signs like depression, ataxia, dropping of lips, muscle fasciculations, bilateral mydriasis, decreased pupillary light reflexes and absence of menace reflex were observed. Clinical signs showed progression up to 36 hours from administration. Supportive treatment with fluids and anti-inflammatory drugs resolved signs in two horses without any long term sequel [7].

\section{Conclusion}

In this way sporadic cases of ivermectin toxicity could be reported in farm animals due to faulty managemental practices by dairy farmer. Such toxicities without specific antidote could be managed with monitoring and supportive therapy till complete clinical recovery.

\section{Conflict of Interest}

The authors declare that there is no conflict of interest regarding the publication of this case report.

\section{References}

1. Campbell WC, Benz GW (1984) Ivermectin: A review of efficiency and safety. Journal of Veterinary Pharmacology and Therapeutics 7: 1-16.

2. McKellar QA, Benchaoui HA (1996) Avermectins and milbemycins. J Vet Pharmacol Ther 19(5): 331-351.

3. Canga AG, Prieto AMS, Liebana MJD, Martinez NFM, Vega MS, et al. (2007) The pharmacokinetics and metabolism of Ivermectin in domestic animal species. The Veterinary Journal 179(1): 25-37.

4. Basudde CDK (1989) Clinical signs and biochemical changes in calves caused by injection of ivermectin. Veterinary Quarterly 11(1): 29-32.

5. Jadhav RK, Bhikane AU, Bhosale AA, Shaikh HA, Jadhav AS (2017) Acute Oxyclozanide-levamisole poisoning in Red Kandhari bulls. Journal of Advanced Veterinary Research 7(1): 16-17.

6. Muller KR, Dwyer C (2016) Suspected levamisole intoxication in calves. N Z Vet J 64(4): 257-260.

7. Swor TM, Whittenburg JL, Chaffin JK (2009) Ivermectin toxicosis in three adult horses. J Journal of American Veterinary Medical Association 235(5): 558-562.

8. Muser RK, Paul JW (1984) Safety of fenbendazole use in cattle. Mod Vet Pract 65(5): 371-374.

9. Vani Prasad V, Koley KM (2006) Treatment of Worm Infestation. In: Synopsis of Veterinary Pharmacology and Toxicology. ( $1^{\text {st }}$ edn), Vahini Publications, India, pp. 235-260.

10. Chiu SHL, Green ML, Baylis FP, Eline D, Rosegay A, et al. (1990) Absorption, tissue distribution, and excretion of tritium labeled Ivermectin in cattle, sheep and rat. Journal of Agriculture and Food Chemistry 38(11): 2072-2078.

11. Molento MB, Lifschitz A, Sallovitz J, Lanusse C, Prichard R (2004) Influence of verapamil on the pharmacokinetics of the antiparasitic drugs Ivermectin and moxidectin in sheep. Parasitology Research 92(2): 121-127. 
Your next submission with Juniper Publishers will reach you the below assets

- Quality Editorial service

- Swift Peer Review

- Reprints availability

- E-prints Service

- Manuscript Podcast for convenient understanding

- Global attainment for your research

- Manuscript accessibility in different formats

( Pdf, E-pub, Full Text, Audio)

- Unceasing customer service

Track the below URL for one-step submission https://juniperpublishers.com/online-submission.php 